\title{
Impact of Cognitive Restructuring and Token Economy Techniques on Truancy Reduction among Secondary School Students in Lagos State, Nigeria
}

\author{
Afolasade Airat Sulaiman*, Stella Ihuoma Uhuegbu \\ Lagos State University, Nigeria \\ @sulaaa@yahoo.co.uk*
}

Article Information:

Received August 24, 2020

Revised October 1, 2020

Accepted October 3, 2020

Keywords: cognitive

restructuring; token economy; truancy; secondary schools

\begin{abstract}
This study examined the impact of cognitive restructuring and token economy techniques on the reduction of truancy among secondary school students in Lagos State, Nigeria. The study adopted a pre-test, post-test, control group design with a multistage sampling technique as the sampling method. Judgmental sampling technique was used to select two from the six Education Districts in Lagos State, simple random sampling technique was adopted to select six schools; three schools from each of the two Education Districts and 170 truants out of the 216 randomly selected based on the class attendance register completed the study. Truancy Behaviour Questionnaire (TBQ) with a reliability index of .87 was the instrument for the study. Data were analysed and presented with descriptive and ANOVA statistics at .05 level of significance. Findings showed that the two techniques were effective for the reduction of truancy but the token economy technique had a better effect. Sex had no significant effect on the reduction of truancy but females play truants more than males. Based on the findings, the token economy therapy was recommended as an ideal technique for counselling and guiding students against truancy.
\end{abstract}

\section{INTRODUCTION}

Truancy is one of the many inappropriate behaviours by students in Nigeria schools. Truancy in this study is an act of leaving school without a good reason at class time and not prior permission to the school. According to UNESCO Institute of Statistics (UIS, 2016) 8.7 million Nigeria children are out of school and more females than males will never get education, they shall be forced to sit at home to take care of their younger ones and do house chores. Earlier, statistics released by the office of Youth and Social Development, an arm of the Lagos State Ministry of Youth, Sports and Social Development showed that of all the identified indiscipline acts among students in Lagos state secondary schools, truancy had the largest number; 2,095 students followed by gangsters, 427 students (Ugbodaga, 2013). Several reasons such as peer pressure, poverty, poor academic performance, poor school environment, lack of transport fare, poor social skills, low self-esteem; lack of parental care and poor parenting style have been reported for truancy (Ehindero, 2015; Makinde, Daodu, \& Topohozin, 2015; Okwakpam \& Okwakpam, 2012; Sulaiman, Shehu, \& Hussaini, 2017). However, Oliha (2014) asserts that thousands of students are absent from school without an excuse.

There appeared to be no consensus in the reports on sex and truancy. Some studies (Igbo \& Ihejiene, 2014; Odu, Alokan, Ibimiluyi, Iretor, \& Olotu, 2015; Whitney, 1998) reported no significant difference between males and females who indulge in truancy. Odu et

How to cite:

E-ISSN:

Published by:
Sulaiman, A., \& Uhuegbu, S. (2021). Impact of Cognitive Restructuring and Token Economy Techniques on Truancy Reduction among Secondary School Students in Lagos State, Nigeria. Islamic Guidance and Counseling Journal, 4(1). https://doi.org/10.25217/igcj.v4i1.1081 2614-1566

Institut Agama Islam Ma'arif NU (IAIMNU) Metro Lampung 
al. (2015) reported that gender does not significantly influence truancy, both male and female students engage in truancy because both sexes are exposed to same psychological, physical, and social environment, which leads to truancy. Hence, males and females play truant equally. Nevertheless, Ehindero (2015), Gesinde (2004), Fareo (2013), Okafor (2012), Siziya, Muula, \& Rudatsikira (2007), Waden \& Zabin (2005) reported males to be more truant than females, Fareo (2013) found significant difference between male and female students' involvement in truancy with a 2.9 mean score for males and 2.7 for females. Ehindero (2015) reported $44.0 \%$ truancy for males and $22.9 \%$ for females. On the contrary, Reid (2000) asserts that females play truants more than males, especially females from poor homes who are made to sit at home to take care of their younger ones, do house chores, get married or hawk for the survival of the family.

The consequences of truancy span through the home, school, community and the students themselves. On the students, the consequence is short-term and long-term. The shortterm effect include maladjustment, poor academic performance, dropping out of school, substance abuse, delinquency, unwanted pregnancy and several other risky psychosocial behaviours while the long term effects are job instability, marital instability, adult criminality and incarceration (Corville-Smith, Ryan, Adams, \& Dalicandro, 1998; Rivers, 2010). Coley, (2011) added that an estimated $95 \%$ of juvenile offenders were those who started as truants. The effects of truancy on schools are loss of funds and failure to meet performance requirements (Goldstein, Little, \& Akin-Little, 2003) while the community is challenged by the presence of students who engage in criminal activities such as robbery, substance abuse, cultism, political thuggery, vandalism and prostitution. Baker, Sigmon and Nugent (2011) assert that such community will have higher government spending for social services and unproductive citizens.

To curb or eradicate truancy, schools adopted some non-therapeutic approaches such as increase supervision, closely monitoring, scolding, punishment and suspension. In addition, as a way of curbing truancy and improving school attendance, the Lagos state government made $70 \%$ cumulative score the condition for free payment of the senior secondary school certificate examination fee. Yet, truancy is evident in schools, many children of secondary school-going age are still seen in entertainment centres, hawking, loitering the streets and engaging in daytime robbery during school hours. Studies (Anyamene, Anyachebelu, \& Anyikwa, 2017; Durosaro, Esere, \& Idowu, 2010; Igborgbor, 1984; Oliha, 2014; Rahmadhony, 2019) also suggested different therapeutic techniques such as value clarification, self-control, self-management, contingency management, group counselling, positive reinforcement, token economy individualized counselling, self-control, cognitive restructuring and systematic desensitization for the reduction of truancy but less focus had been on the use of token economy as a technique and the combination of cognitive restructuring and token economy as therapies for the reduction of truancy among students in Nigeria secondary schools. Hence, this study chose to examine the effectiveness of the two therapies- cognitive restructuring and token economy for the reduction of truancy.

Cognitive restructuring is one of the numerous techniques used by cognitive behavioural therapist to help clients become aware of the connections between their thoughts, emotions and behaviours. Cognitive restructuring is a central technique of cognitive therapy that teaches people how to improve themselves by replacing faulty cognitions with constructive beliefs (Corey, 2009). The overall intention when using cognitive restructuring is to help clients move away from more extreme and unhelpful ways of seeing things to more helpful and balanced conclusions. Clients can realize that life does not always work out the way they would like it but can be bearable (McLeod \& McLeod, 2011). McLeod (2015) asserts that clients learn to distinguish between thoughts and feelings by 1) becoming aware of the ways in which thoughts can influence feelings in unhelpful ways, 2) learning about 
thoughts that seem to occur automatically, without even realizing how they may affect emotions, 3) evaluating critically whether these automatic thoughts and assumptions are accurate or biased, 4) developing the skills to notice, interrupt and correct these biased thoughts independently, thereby leading to change in attitude, which also affect personality in a positive direction. Studies (Addison, Antwiand, \& Avonokadzi, 2014). Studies (Adewusi, 2013; Mora, 2011; Oliha, 2014; Adeyemi \& Uwakwe, 2014; Aderanti \& Hassan, 2011; Durosaro, et al. 2010) have shown that cognitive restructuring is highly effective on the treatment of truancy among secondary school students and various forms of antisocial behaviours. Mora (2011) and Oliha (2014) reported the effectiveness of cognitive restructuring in truancy reduction among secondary school students in Nigeria while others confirmed the effectiveness of cognitive restructuring and other therapies in the reduction truancy among secondary school students.

Token economy is a behaviour intervention strategy designed to create a positive opportunity by using reinforcers to increase individuals' extrinsic motivation which comes from external factors (Britta, 2014). Christopher, Doll and Barreto (2013) assert that token economy can be in different forms and have an age long usage till date. Token economy had been widely used in several settings such as addiction treatment facilities, correctional centres, care centres, schools, industries and mental homes. Britta (2014) avers that the flexibility of token economy is one of its most desirable features that makes it easy to apply in a variety of settings and population. Therapeutic studies (Britta, 2014; Carnett, Raulston, Lang, Tostanoski, Lee, Sigafoos, \& Machalicek, 2014; Lewis, 1995; Nelson, 2010; Ogunwole, Bello \& Zakariyah, 2017; Rahmadhony, 2019; Reitman, Murphy, Stephen, Hupp, \& O'Callaghan, 2004; Sran \& Borrero, 2010) on token economy reported positive effects on respondents' behaviour, after the introduction of token economy, there were significant reduction in disruptive behaviours compared to baseline rates. However, the use of token economy for the reduction of truancy is scarce in the literature, studies focused more on academic achievement, classroom disruptive behaviours and other maladjustive behaviours. Maggin, Chafouleas, Goddard and Johnson (2011) assert that token economy has been used in the improvement of social and academic skills, attention, speech, drug addiction, self-care and disruptive behaviours. Britta (2014), Nelson (2010), Aljuhaish (2015) and Ogunwole et al. (2017) studies were on token economy and classroom performance, participation and achievement. Reitman et al. (2004) reported decrease in classroom disruptive behaviours for token economy while Carnett et al. (2014) study was on token economy and autistic behaviour. Only the studies of Rahmadhony (2019) and Lewis (1995) out of the reviewed literature focused on token economy and truancy.

In addition, therapeutic studies on truancy did not combine the use of token economy with cognitive restructuring. Adeyemi and Uwakwe (2014) combined cognitive restructuring with social-decision making techniques for the increase in school attendance, Oliha (2014) combined contingency management and cognitive restructuring for truancy reduction while Mora (2011) used only cognitive restructuring technique and Igborgbor (1984) earlier used value clarification techniques for truancy reduction. Hence the focus of this study, what will be the outcome of combining token economy with cognitive restructuring in the reduction of truancy and which of the two therapies will be more effective?

\section{Rationale of the Current Study}

To ensure the development of a fully functioning individual that will contribute effectively to national development, the counsellor is always concerned about students' overall adjustment. Since truancy is identified as a gateway to crime, delinquent behaviors and low human capital potentials, it defeats the philosophy of Nigeria national policy on education and calls for appropriate counselling intervention. As earlier noted, several studies 
have suggested different therapeutic techniques for the reduction of truancy but few studies have focused on the use of token economy as a technique and the combination of cognitive restructuring and token economy as therapies for the reduction of truancy among students in Nigeria secondary schools. Hence, this study chose to examine the effectiveness of the two therapies- cognitive restructuring and token economy for the reduction of truancy among secondary school students in Lagos state, Nigeria.

\section{Hypotheses}

1. There is no significant effect of treatment on truancy reduction among secondary school students in Lagos State.

2. There is no significant interaction effect of treatments and sex on truancy reduction among secondary school students in Lagos State.

3. There is no significant main effect of treatments on truancy reduction among secondary school students in Lagos State.

4. There is no significant main effect of sex on truancy among secondary school students.

\section{METHODS}

\section{Research Design}

The design adopted for the study was experimental; $3 \times 2$ pre-test, post-test, control group. The choice of the design was because the study met the conditions for experimental design, which are randomization, homogeneity of variables and the use of treatments cognitive restructuring and token economy. Participants were exposed to the same instrumentTruant Behaviour Questionnaire (TBQ) before and after treatment. Each school was assigned to only one of six groups by simple random sampling. Truants from each school- 36, 18 males and 18 females were randomly assigned to each group, two schools for each treatment.

\section{Participants}

The sample selected for the study was 216 male and female truants from six randomly selected public secondary school in Lagos state. Though, due to attrition only 170 completed the treatment. Participants whose age range from 11-19 years were randomly selected from the number of students identified as truants in each of the selected schools. Three schools were randomly selected from two Education Districts and 36 truants' 18 males and 18 females were randomly selected. Judgmental sampling technique was used to select the two Education Districts from the six Education Districts in Lagos state, the choice of the two districts was premise on densely population and adequate representation of all socio-economic strata in the state. Truants were identified from the class attendance register, those having incredibly low attendance, students who were absent from school for a minimum of 20 days out of the 110 days in each of the first and second school term.

\section{Instrument}

The instrument for the study was the Truancy Behaviour Questionnaire (TBQ). TBQ is a self-developed tool, which was divided into two sections. The first section required demographic information such as age, sex, religion and class from respondents. The second section consist of 41 items on truancy such as hang out with friends, got tired of school, needed a break from school, in conflict with peers, not comfortable in class, too many difficult subjects, too many difficult questions from teachers. The rating of TBQ was fourpoint- Strongly Agree $=4$ points, Agree $=3$ points, Disagree $=2$ points and Strongly Disagree $=1$ point. The minimum obtainable score was 30 while the maximum was 120 , low scores indicate casual/low truancy and high scores 65-120 was habitual truancy. 
Face and content validity for TBQ was established by psychometric experts and Faculty members of Lagos State University, Counselling Department. In establishing content validity, experts and target group's recommendations were adopted on grammar, using appropriate and correct words, applying correct and proper order of words in items and appropriate scoring. Reliability of TBQ was determined using Cronbach Alpha value. The instrument was administered to a sample of 60 truants who were purposely selected from secondary schools in one of the Education Districts outside of the selected Districts for the study. TBQ yielded a reliability index of .87 , which declared the instrument reliable.

\section{Treatment Package}

\section{Cognitive Restructuring: Treatment group 1}

The package was an eight sessions of 45 minutes per session for eight weeks, designed to assist participants to restructure their negative thought and attitude towards school attendance. The first session focused on the enlightenment of participants on the purpose of the programme and pre TBQ test, the next six sessions were for treatment, participants were taught cognitive restructuring strategies and the last session was for post TBQ test.

\section{Token Economy Technique: Treatment group 2}

The package had two parallel sessions; token award and 45 minutes of intervention for eight weeks. Token award sessions involved daily monitoring of participants by the class teachers on class attendance and the award of tokens to deserving participants. Tokens were exchanged for tangible items; balls, lunch, quality white socks, and mathematical sets by the researcher. As in cognitive restructuring, the first session of the intervention programme was for introduction and enlightenment on details of programme and pre TBQ test. The next 6 sessions were for treatment, teaching of skills and the last session was for conclusion and post TBQ test.

\section{Data Analysis}

Data was analysed using descriptive statistics- mean score and standard deviation for hypothesis one and inferential statistics- ANOVA for the other hypothesis. Tukey honestly significant difference (HSD) test was adopted for the direction of the difference in results.

\section{RESULTS AND DISCUSSION}

\section{Results}

Pre-treatment and post-treatment scores of respondents on TBQ were compared. Results presented in Table 1 show the effect of treatment in the reduction of truancy across groups. Low mean score 55.78, 48.63 indicated drastic reduction in truancy for respondents in the treatment groups; cognitive restructuring and token economy with a sharp contrast to the mean score 70.94 of respondents in the control group. High scores on TBQ is an indication of truancy for respondents.

To explore the impact of treatment- cognitive restructuring and token economy on truancy reduction and the interaction effect of sex, a two-way between-groups analysis of variance was conducted. Respondents were divided into three groups: cognitive restructuring,

Table 1. Effect of Treatment on Truancy Reduction

\begin{tabular}{llllll}
\hline \multirow{2}{*}{ Groups } & \multirow{2}{*}{$\mathrm{N}$} & \multicolumn{3}{c}{ Pre-treatment } & \multicolumn{3}{c}{ Post-treatment } \\
\cline { 3 - 6 } & & Mean & SD & Mean & SD \\
\hline Token Economy & 72 & 75.56 & 6.57 & 48.63 & 7.82 \\
Cognitive Restructuring & 45 & 75.42 & 9.70 & 55.78 & 5.91 \\
Control Group & 53 & 73.61 & 8.64 & 70.94 & 9.97 \\
\hline
\end{tabular}


Table 2. ANOVA Test of Treatment Effect and Interaction Effect of Sex on Truancy Reduction

\begin{tabular}{lllllll}
\hline Source & $\begin{array}{l}\text { Type III Sum of } \\
\text { Squares }\end{array}$ & df & Mean Square & F & p & $\begin{array}{l}\text { Partial Eta } \\
\text { Squared }\end{array}$ \\
\hline Corrected Model & $15435.617^{\mathrm{a}}$ & 5 & 3087.123 & 46.048 & .000 & .584 \\
Intercept & 536091.603 & 1 & 536091.603 & 7996.426 & .000 & .980 \\
Treatment & 15211.074 & 2 & 7605.537 & 113.445 & .000 & .580 \\
Sex & 39.368 & 1 & 39.368 & .587 & .445 & .004 \\
Treatment * Sex & 22.137 & 2 & 11.069 & .165 & .848 & .002 \\
Error & 10994.789 & 164 & 67.041 & & & \\
Total & 588033.000 & 170 & & & & \\
Corrected Total & 26430.406 & 169 & & & & \\
\hline
\end{tabular}

R Squared $=.584($ Adjusted R Squared $=.571)$

Table 3. Post-Hoc of Significant Main Effect for Treatment

\begin{tabular}{lllll}
\hline Treatment I & Treatment J & Mean Diff. (I-J) & Std. Error & Sig. \\
\hline Token & Cognitive & $-6.950^{*}$ & 1.599 & .000 \\
& Control & $-22.244^{*}$ & 1.486 & .000 \\
Cognitive & Token & $6.950^{*}$ & 1.599 & .000 \\
& Control & $-15.294^{*}$ & 1.703 & .000 \\
Control & Token & $22.244^{*}$ & 1.486 & .000 \\
& Cognitive & $15.294^{*}$ & 1.703 & .000 \\
\hline
\end{tabular}

*** The mean difference is significant at the .05 level.

token economy and control based on the number of times they were absent from school, 20 days out of 110 days as indicated on the school attendance register. Results presented in Table 2 show that the interaction effect between treatment group and sex was not statistically significant, $F(2,164)=.17, P=.85$.

There was a statistically significant main effect for treatment, $F(2,164)=113.45, P=$ .00 but no statistically significant main effect for sex, $F(1,164)=.59, P=.45$. Hence, indicating that reduction in truancy is not dependent on sex, being male or female does not influence truancy reduction and males and females do not differ in terms of their truancy scores, but there is was a difference in scores for treatment groups

Further, post-hoc comparisons using the Tukey HSD test presented in Table 3 was conducted to identify the area of significance and ascertain the better of the two techniques for the reduction of truancy. The mean scores for the token economy group, $\mathrm{M}=48.63$. $\mathrm{SD}=$ 7.82 and the cognitive restructuring group, $\mathrm{M}=55.78 . \mathrm{SD}=5.91$ were significantly different from the control group's mean score, $\mathrm{M}=70.94, \mathrm{SD}=9.97$ with mean difference score 22.24, 15.30 respectively. This indicated that both treatments were appropriate for the reduction of truancy but token economy with a lower truancy mean score, a higher mean difference from control group and a 6.95 mean score difference from cognitive restructuring is more appropriate for the reduction of truancy among participants.

\section{Discussion}

The significant main effect of treatment confirmed the effectiveness of cognitive restructuring and token economy as appropriate strategies for the reduction of truancy. Several studies (Adewusi, 2013; Oliha, 2014; Adeyemi \& Uwakwe, 2014; Aderanti \& Hassan, 2011; Durosaro, et. al 2010; Mora, 2011) earlier reported the efficacy of cognitive restructuring for truancy reduction and various forms of antisocial behaviours. Mora (2011) and Oliha (2014) reported the effectiveness of cognitive restructuring in truancy reduction among secondary school students in Nigeria. Though few studies were reported for token economy and truancy reduction but numerous studies have reported its efficacy for the reduction of disruptive behaviours in a various settings and population (Britta, 2014; Carnett, 
et al. 2014; Lewis, 1995; Nelson, 2010; Ogunwole, Bello \& Zakariyah, 2017; Rahmadhony, 2019; Reitman et al. 2004; Sran \& Borrero, 2010). Rahmadhony (2019) and Lewis (1995) reported the efficacy of token economy for the reduction of truancy.

In addition, token economy technique was found to be more effective for the reduction of truancy than cognitive restructuring technique. The fact that students in the token economy groups did not play truant during the treatment period proved that truant behaviour is amendable when reinforcement inform of tokens are applied. Participants were looking forward to receiving gifts for attending school for the week. The effectiveness of token economy could therefore be attributed to its reward system.

There is the need for students to take responsibility for their actions. They should become goal oriented and intrinsically motivated not to get trapped in negative peer attitude, but rather imbibe honourable qualities in themselves. Hence the teaching of different personal and social skills becomes mandatory.

Parents need to be more involved in their wards school activities through regular update and follow up on their specific needs, school attendance and performance. Parents will also need to learn appropriate parenting skills to imbibe self-discipline and foster worthwhile development of their wards. Parents should stop being stereotyped, no preferential treatment should be given to any particular sex. Females should be treated same as boys even in schooling.

Teachers must adopt individualized strategies to motivate students' school attendance such as 1) identify poor students in order to get supports for their needs such as scholarships, sponsorships, medical care, social support, counselling and legal assistance, 2) dentify classroom challenges such as bullies and curtail their acts not to frighten the weak from attending classes, 3 ) ensure students are actively involved in learning by giving different tasks and follow-up strictly with prompt feedbacks, 4) adopt the use of different teaching method with adequate visual learning aids such as graphics, charts, diagrams, photographs and most importantly real objects, 5) endeavour to take classroom attendance regularly; twice dailymorning and afternoon, to detect students who miss school daily and to promptly get their parents informed thereby nipping truancy in the bud, and 6) appropriate punishment methods should be adopted in place of hard labour and corporal punishment for erring students.

Government must become more serious by enacting strict truancy laws, which will force parents to be more involved in the schooling and wellbeing of their wards thereby reducing truancy and increasing school attendance. Placement of professional counsellors into schools and the provision of functional and well-equipped counselling centres. The Nigeria national policy on education emphasized the importance and need of counsellor in schools. The present act of not placing counsellors into schools and not allowing the few placed into schools to function fully as counsellors negates the National policy on Education. The presence of fully functioning counsellors to manage the personal, social, vocational and academic needs of students will go a long way in ensuring preventive interventions. Appointment of school counsellors for school counselling programmes will foster synergy between the home and school, encourage the learning of appropriate parenting skills, positive practice in punishment as well as rules and regulation guiding punishment.

Counsellors will inculcate truancy reduction programmes into the school counselling programme. Emphasis will be on teaching erring students' appropriate truancy reduction therapies more importantly token economy as found in this study and self-management skills that could help students challenge their self-defeating thoughts, change their irrational beliefs, substitute realistic perceptions and develop positive self. The school counsellor in collaboration with the school authority will create intensive awareness on value orientation and emphasis on the damaging effect of truancy and the attendant consequences. 
Massive enlightenment programmes through the media: print, social, electronic on truancy implications for truants and the responsibilities of all concerned in ensuring its eradication. Emphasis must be on the need of our community to revisit the "collectiveness" of our community; "the I am because we are". No student must be allowed to play truant. The responsibility of checking and reporting any school age child found out of school during school hours fall on all adults. Any school age child found out of school during school hours should be reported to the school, the parent or concerned authorities.

\section{Limitations and Suggestions}

Even though, no significant interactive and main effect were found for sex, yet, it was observed that females play truants more than males, a significant number of the students sampled for the study did not complete the eight weeks of treatment; 46, 32 females and 14 males of the 216 sampled. This further emphasized the prevalence of truancy among students in Lagos state secondary schools, confirmed the disparity in the literature for sex and truancy and validate Fareo (2013) and Reid (2000) assertion that females played truants more than males. UNESCO Institute of Statistics (UIS, 2016) reported that females may never have the opportunity of schooling because they would be forced to sit at home to take care of their younger ones and do house chores. The no interaction effect for sex corroborate Odu et al. (2015) and Igbo and Ihejiene (2014) report that males and females played truant equally, being a male or female has no influence on being a truant because truancy is a learned behaviour that both sexes are exposed to. Both sexes are exposed to same psychological, physical, and social environment, which leads to truancy. This perhaps also served as the limitation for the study as the researchers were not able to hold the students in the groups throughout the study.

Hence, further studies should be carried out at other school strata: primary, higher institutions to ascertain if truancy is actually a learned culture which is played across all levels of education and socio-economic status. Other studies could also examine the effectiveness of token economy with other counselling techniques.

\section{Implications}

The findings of this study pointed to the need for counsellors to adopt individualised and preventive counselling, hence, there is need to 1) focus more on the casual factors of truancy and ensure interventions are directed towards preventing the manifestation of such factors, 2) establish synergy between the school and home, teaching appropriate parenting style and truancy identification strategies, 3) constantly highlight the consequences of truancy on students' present and future endeavour, 4) collaborate with the school administrators to monitor teachers and their teaching styles including effective use of instructional materials to facilitate learners' interest in subjects and schooling, 5) organise training for teachers on different skills and techniques that could facilitates teach and learning as well as behavioural change.

\section{CONCLUSIONS}

The thesis of this study to determine the efficacy of cognitive restructuring and token economy techniques for the reduction of truancy among students in Lagos secondary schools has been achieved. This study has been able to provide information on appropriate therapy for the reduction of truancy and the process of achieving same. Token economy with its reward system appeared more appropriate for the reduction of truancy, it has emphasised the importance of rewards in place of punishment and that of skills training instead of merely offering information. Teaching learners how to become responsible for their actions is more effective than passing instruction on what must not be done. Also it has been established that 
females played truants more than males, thus calling for attitudinal change. The burden of family care should be lifted from the shoulders of females and their schooling should not be mortgaged for any reason whatsoever. Going by the policy on education to appoint fully functioning counsellors that will develop a functional counselling programme for the school will go a long way in facilitating the eradication of truancy in schools.

\section{ACKNOWLEDGEMENTS}

We sincerely appreciate the cooperation of the administrators, teachers and students of the schools used for the study.

\section{AUTHOR CONTRIBUTIONS STATEMENT}

AAS organised and supervised the treatment setting, validated the instrument and the treatment packages, analysed the data generated and wrote the manuscript. SIU organised students in the sampled schools, carried out the treatments, testing and generated results for statistical analyses.

\section{REFERENCES}

Addison, A. K., Antwi, T. \& Avonokadzi I. K. (2014). Impact of cognitive restructuring on students with low self-esteem and academic performance in Dambai College of Education in Volta region of Ghana. Projournal of humanities and social sciences 2(3), 125-141. Retrieved from Google Scholar

Aderanti, R.A. \& Hassan, T. (2011). Differential effectiveness of cognitive restructuring and self-management in the treatment of adolescents. The Romanian Journal of Psychology, Psychotherapy and Neuroscience, 1(1), 193-217. Retrieved from Google Scholar

Adewusi, S. O. (2013). Efficacy of cognitive restructuring and behavioural rehearsal on conduct disorder in adolescents in Special Correctional Centres in Lagos State (An Unpublished $\mathrm{PhD}$ thesis submitted to the Department of Psychology, Covenant University, Ota, Ogun State, Nigeria). Retrieved from Google Scholar

Adeyemi, A. O., \& Uwakwe, C. B. U. (2014). Effectiveness of cognitive restructuring and social decision-making techniques on truancy behaviour reduction among secondary school adolescents in Ibadan, Nigeria. African Journal for the psychological study of social issues, 17(2), 67-77. Retrieved from Google Scholar

Aljuhaish, S. F. (2015). The effectiveness of behaviourist's token economy system on teaching English as a second language at Saudi schools in Kuala Lumpur. International Journal of Novel Research in Education and Learning, 2(3), 43-49. Retrieved from Google Scholar

Anyamene, A., Anyachebelu, F. E., \& Anyikwa, N. (2017). Effects of individualized counselling technique on remedying truancy among junior secondary school students. Journal of Guidance and Counselling Studies, 1(1), 15-19. Retrieved from Google Scholar

Baker, M. L., Sigmon, J. N., \& Nugent, M. E. (2011). Truancy reduction: Keeping students in school. Office of Juvenile Justice and Delinquency Prevention Bulletin. Retrieved from Google Scholar

Britta, L. F. (2014). A comparison of the effectiveness of a token economy system, a response cost condition, and a combination condition in reducing problem behaviours and increasing student academic engagement and performance in two first grade classrooms (Unpublished thesis, Minnesota state university, Mankato). Retrieved from Google Scholar 
Carnett, A., Raulston, T., Lang, R., Tostanoski, A., Lee, A., Sigafoos, J., \& Machalicek, W. (2014). Effects of a preservative interest-based token economy on challenging and ontask behaviour in a child with autism. Journal of behavioural education, 23(3), 368377. https://doi.org/10.1007/s10864-014-9195-7

Coley, R. J. (2011). Dreams deferred: High school dropouts in the united states. Princeton, $\mathrm{NJ}$ : educational testing service, policy information centre. Retrieved from Google Scholar

Corey, G. (2009). Theory and practice of counselling and psychotherapy (8th ed.). Belmont, USA: Thomson Higher Education. Retrieved from Google Scholar

Corville-Smith, J., Ryan, B. A., Adams, G. R., \& Dalicandro, T. (1998). Distinguishing absentee students from regular attenders: The combined influence of personal, family, and school factors. Journal of Youth and Adolescence, 27 (5), 629-640. https://doi.org/10.1023/A:1022887124634

Christopher, N. H., Doll, T. M., \& Barreto, A. (2013). The taken economy: A recent review and evaluation. International journal of Basic and Applied Science, 2(1), 131-149. Retrieved from Google Scholar

Durosaro, I., Esere, M. O. \& Idowu, A. (2010).Efficacy of group counselling interventions positive reinforcement and self-control techniques in remedying truancy among schoolgoing adolescents in Ilorin, Nigeria. IFE PsychologIA : An International Journal, 18 (1), 45-54. https://hdl.handle.net/10520/EJC38800

Ehindero, S. A. (2015) Truancy among public secondary school students. Implications for counselling: Research journal in organizational psychology and educational studies, 4(3), 85-92. Retrieved from Google Scholar

Fareo, D.O. (2013). Truancy and academic performance of secondary school students in south-western Nigeria: implication for counselling. International journal for crossdisciplinary subjects in education, special issue, 3 (2), 20-23. Retrieved from Google Scholar

Gesinde, A. M. (2004). Psychosocial determinants of truant behaviour among secondary school students. Ife Psychologia: An international journal 13(1), 188-199. Retrieved from Google Scholar

Goldstein, J. S., Little, S. G., \& Akin-Little, A. (2003). Absenteeism: A review of the literature and school psychology's role. The California School Psychologist, 8. https://doi.org/10.1007/BF03340901

Igbo, J. N. \& Ihejiene, M.A. (2014). Gender differences, delinquent behaviours and academic achievement of secondary school students in Nigeria. International journal of latest research in science and technology,3 (4), 40-46. Retrieved from Google Scholar

Igborgbor, G. C. (1984). Comparison of values clarification and contingency management techniques in the treatment of truancy (Unpublished PhD. thesis, University of Ibadan). Retrieved from Google Scholar

Lewis, C. (1995). Improving attendance- reducing truancy: a school based approach. Educational Psychology in Practice, 11(1), 36-40. https://doi.org/10.1080/0266736950110105

Maggin, D.M., Chafouleas, S.M., Goddard, K.M. and Johnson, A.H. (2011). A systematic evaluation of token economies as a classroom management tool for students with challenging behaviour. Journal of school psychology, 49(5), 5299-5554. https://doi.org/10.1016/j.jsp.2011.05.001

Makinde, B, O., Daodu, M. A., \& Topohozin, K. D. (2015). Peer pressure and parenting styles as predictors of truancy behaviour among senior secondary school students in Badagry Local Government Area. The Lagos Counsellor, 8 (1), 17-34. 
McLeod, J., \& McLeod, J. (2011). Counselling skills: A practical guide for counsellors and helping professionals ( $2^{\text {nd }}$ ed.). Berkshire, England: McGraw-Hill, Open University Press. Retrieved from Google Scholar

McLeod, S. A. (2015). Skinner operant conditioning. Retrieved from Google Scholar

Mora, H. I. (2011). Effects of cognitive restructuring on truancy among senior secondary school students in Kaduna metropolis. The counsellor, 30(2). 92-104. Retrieved from Google Scholar

Nelson, K. G. (2010). Exploration of classroom participation in the presence of a token economy. Journal of Instructional Psychology, 37 (1), 49-56. Retrieved from Google Scholar

Odu, B. K., Alokan, F. B., Ibimiluyi, F., Iretor, O.B., \& Olotu, O.A., (2015). Influence of gender and age on behavioural problems and experience of child abuse among secondary school students. British Journal of Education, 3(10), 22-34. Retrieved from Google Scholar

Ogunwole, E. A., Bello, R. M., \& Zakariyah, A. A. (2017). Effect of token economy counselling technique on disruptive classroom communication behaviour among secondary school students in Zaria Metropolis. Ibadan Journal of Sociology, 6, 27-40. Retrieved from Google Scholar

Okafor, R. (2012). The influence of socio-Economic background on self-concept and academic achievement of senior secondary school II students in Aguata educational zone of Anambra state (Unpublished M.Ed. project University of Nigeria, Nssuka).

Okwakpam, I. N., \& Okwakpam, I. O. (2012). Causes and levels of truancy among secondary school students: A case study of rivers state, Nigeria. Problems of education in the 21st century, 45, 51-62. Retrieved from Google Scholar

Oliha, J.A. (2014). Differential effectiveness of contingency management and cognitive restructuring in the reduction of truancy among secondary school adolescents. Journal of studies in social sciences, 6(1), 15-22. Retrieved from Google Scholar

Rahmadhony, S. (2019). The Effectiveness of Token Economy to Reduce Truant Behaviour International Journal of Education \& Curriculum Application, 2(1), 24-30. Retrieved from Google Scholar

Reid, K. (2000). Tackling truancy in schools. A practical guide for primary and secondary schools. London: Routledge. Retrieved from Google Scholar

Reitman, D., Murphy, M. A., Stephen D. A., Hupp, P. M., \& O'Callaghan, M. A. (2004). Behaviour change and perceptions of change: Evaluating the effectiveness of a token economy. Child \& Family Behaviour Therapy, 26(2), 17-36. https://doi.org/10.1300/J019v26n02_02

Rivers, B. (2010). Truancy: Causes, effects and solutions (Education masters. Pg. 107). Retrieved from Google Scholar

Shobola, A. A. (2011). The study of the effects of cognitive restructuring on cigarette smoking behavior of undergraduate students. Ife Psychologia, 16(1), 187-197. Retrieved from Google Scholar

Siziya, A., Muula, S. S. \& Rudatsikira, E. (2007). Prevalence and correlate of truancy among student in Swaziland: findings from the global school-based health survey. Journal of child and adolescent psychiatry and mental health, 1, 15. https://doi.org/10.1186/17532000-1-15

Sran, S. K. \& Borrero, C. (2010). Assessing the value of choice in a token system. Journal of Applied Behaviour Analysis, 43(3), 553-557. https://doi.org/10.1901/jaba.2010.43-553

Sulaiman, A. A., Shehu, H., \& Hussaini, N. (2017). Impact of physical facilities on discipline, extra-curricular activities and teaching and learning in Mable secondary schools, 
Impact of Cognitive Restructuring and Token Economy Techniques on Truancy Reduction among Secondary School Students in Lagos State, Nigeria

Uganda. The Malaysia Journal of Psychology, 31(1), 20-28. Retrieved from Google Scholar

Ugbodaga, K. (2013). Fifty-four pregnant females in Lagos public schools. Retrieved from https://www.pmnewsnigeria.com

UNESCO, I. S. (2016). Leaving no one behind: How far on the way to universal primary and secondary education?. Retrieved from http://uis.unesco.org

Waden, M. M., \& Zabin, L. S. (2005). Gender and ethnic differences in the co-occurrence of adolescent risk behaviours. Ethn health, 10(3), 213-234. https://doi.org/10.1080/13557850500115744

\author{
Copyright holder : \\ (C) Sulaiman, A., \& Uhuegbu, S. (2021) \\ First publication right : \\ Islamic Guidance and Counseling Journal \\ This article is licensed under: \\ CC-BY-SA
}

